\title{
HIGH TIBIAL OSTEOTOMY USING A LOCKING TITANIUM PLATE WITH OR WITHOUT AUTOGRAFTING
}

\section{OSTEOTOMIA TIBIAL ALTA COM PLACA BLOQUEADA DE TITÂNIO COM OU SEM AUTOENXERTO}

\author{
Hakan Sarman ${ }^{1}$, Cengiz Isik ${ }^{2}$, Mustafa Uslu ${ }^{3}$, Mustafa ERkan Inanmaz ${ }^{4}$ \\ 1. Private Ethica Incirli Hospital, Department of Orthopedics and Traumatology, Istanbul, Turkey. \\ 2. Abant Izzet Baysal University, School of Medicine, Department of Orthopedics and Traumatology, Bolu, Turkey. \\ 3. Isparta City Hospital, Department of Orthopedics and Traumatology, Isparta, Turkey. \\ 4. Sakarya University, School of Medicine, Department of Orthopedics and Traumatology, Sakarya, Turkey.
}

\section{ABSTRACT}

Objective: To postoperatively evaluate knee scores, radiological assessment results, deficit correction, patellar height change, bone healing time, and weight bearing time in patients undergoing high tibial osteotomy (HTO) with/without autologous iliac bone grafting. Methods: This retrospective examination of treated controls from a randomized controlled study included 63 knees of 58 patients aged $46-59$ years who underwent HTO with locking open wedge osteotomy plates. The patients were divided into two groups: Group A, HTO with autologous iliac bone grafts ( $n=31)$; and Group B, HTO without autologous iliac bone grafts $(n=32)$. Clinical and radiological data were evaluated prospectively at the preoperative consultation and again at 6,9 , and 12 weeks, 6 months, and 1 year after the surgery (and annually thereafter). Results: There were no significant intergroup differences in the radiological assessment, deficit correction, patellar height change, bone-healing time, and weight-bearing time at any time after surgery. The knee scores changed positively in both groups ( $p<0.001$ ). Conclusions: There was no difference in the results of patients undergoing HTO with open wedge osteotomy titanium locking plates with or without autografting, and comorbidities resulting from autografts were eliminated with the use of locking plates. Level of evidence III, Retrospective Study.

Keywords: Autograft. Healing. Correction. Osteotomy. Bone plate. Tibia.

\section{RESUMO}

Objetivo: Avaliar escores de joelho, resultados da avaliação radiológica, correção de déficits, alteração da altura patelar, tempo de consolidação óssea e tempo para apoio de peso no pós-operatório em pacientes submetidos à osteotomia tibial alta (OTA) com ou sem enxerto autólogo de osso ilíaco. Métodos: O exame retrospectivo de controles tratados em estudo randomizado e controlado foi realizado em 63 joelhos de 58 pacientes com idade entre 46 e 59 anos submetidos a OTA com placas bloqueadas de titânio em cunha aberta. Os pacientes foram divididos em dois grupos: Grupo A, OTA com enxerto de osso ilíaco autólogo $(n=31)$ e Grupo B, OTA sem enxerto autólogo de osso ilíaco $(n=32)$. Os dados clínicos e radiológicos foram avaliados prospectivamente na consulta pré-operatória e 6, 9 e 12 semanas e 6 meses e 1 ano após a cirurgia (e depois disso, anualmente). Resultados: Não houve diferenças significativas quanto a avaliação radiológica, correção de déficit, mudança de altura da patela, tempo de cicatrização óssea e tempo para apoio de peso entre os dois grupos em nenhum momento após a cirurgia. Os escores de joelho mudaram positivamente em ambos os grupos ( $p<0,001)$. Conclusões: Não houve diferença nos resultados dos pacientes submetidos a OTA com placas bloqueadas de titânio em cunha aberta com e sem autoenxerto, e as comorbidades resultantes dos autoenxertos foram eliminadas com o uso de placas bloqueadas. Nível de Evidência III, Estudo Retrospectivo.

Descritores: Autoenxertos. Cura. Correção. Osteotomia. Placas ósseas. Tíbia.

Citation: Sarman H, Isik C, Uslu M, Inanmaz ME. High tibial osteotomy using a locking titanium plate with or without autografting autografting. Acta Ortop Bras. [online]. 2019;27(2):80-4. Available from URL: http://www.scielo.br/aob.

\section{INTRODUCTION}

Angular deformities of the knee are a common cause of knee pain. Genu varum and osteoarthritis will increase within the elderly population in most countries along with increases in knee surgeries such as arthroscopy, high tibial osteotomy, and total knee arthroplasty. ${ }^{1,2}$ Jackson ${ }^{3}$ first described high tibial osteotomy (HTO) in 1958 and it was further popularized by Coventry. ${ }^{4}$ HTO has become a popular treatment option for varus unicompartmental gonarthrosis, osteochondral lesions, and joint instability in young and active patients. ${ }^{5,6}$ Although many surgical techniques for HTO have been described, including the dome, llizarov, medial opening-wedge, and lateral closing-wedge techniques, medial opening-wedge

All authors declare no potential conflict of interest related to this article. 
high tibial osteotomy (MOWHTO) has become more popular over the past two decades and has a lower rate of complications. ${ }^{5-8}$ In MOWHTO, different fixation techniques are applied with or without using bone grafts, ${ }^{7,9-11}$ autografts are usually used to fill the osteotomy defect, although allografts (tricalcium phosphate, dicalcium phosphate granules, acrylic cement, or hydroxyapatite) and xenografts have also been used..$^{711,12}$ Autogenous bone grafts prolong the operating time and increase morbidity, including severe chronic donor site pain, infection, palpable defects, paresthesias, and increased blood loss. ${ }^{7,9,10}$ Some studies have demonstrated that the bone union rates did not differ significantly with or without a graft in an opening-wedge HTO. ${ }^{10,13}$ However, when grafts or locking plates were not used, a correction deficit and delayed bone union were reported. ${ }^{12,14}$

Therefore, this study examined differences between patients undergoing MOWHTO with a locking titanium plate with or without autografts by two surgeon's technique, according to knee score, radiological assessment, deficit correction, patellar height change, bone healing time, weight bearing time, and complication rate. Additionally, we elevated whether bone grafting is necessary or not for HTO.

\section{MATERIALS AND METHODS}

\section{Study Design}

This retrospective study evaluated 63 knees of 58 patients who had undergone MOWHTO with an open wedge osteotomy (OWO) titanium locking plate (TST Tibbi Aletler, Istanbul, Turkey) (Figure 1) performed at the different medical center by two surgeon's experience $(\mathrm{Cl}$ and $\mathrm{HS})$ in patients with isolated varus unicompartmental gonarthrosis between December 2011 and September 2014. Group A consisted of 31 osteotomies were operated by the Surgeon $\mathrm{Cl}$ in which the osseous tibial defect was filled with autologous iliac bone graft. Group B consisted of 32 osteotomies were by the Surgeon HS in which the osseous tibial defect was not filled. Inclusion and exclusion criteria are summarized in Table 1. All patients underwent arthroscopic debridement and assessment before MOWHTO. All patients undergoing $\mathrm{HTO}$ were evaluated pre- and postoperatively in terms of range of motion (ROM), Knee Society Score, and Functional Knee Society Score.

\section{Radiological evaluation}

Preoperatively, anteroposterior (AP), lateral, and tangential X-rays and magnetic resonance imaging (MRI) of the knee were obtained for patients scheduled to undergo MOWHTO. In pre- and postoperative images, the following measurements were made: the mechanical axis of deviation (MAD), medial proximal tibial angle (MPTA), Insall-Salvati Index (ISI), and Blackburne-Peel Ratio (BPR). The clinical and radiological data were evaluated prospectively at the preoperative consultation and 6, 9, and 12 weeks, and 6 months and 1 year, after the surgery, and then annually. Bone union was

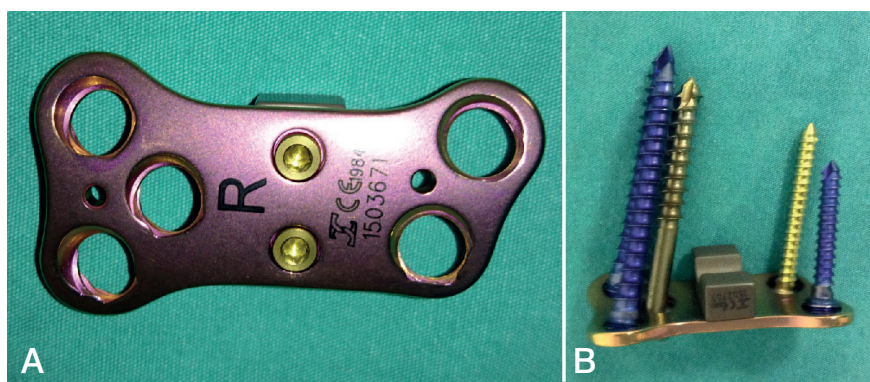

Figure 1. A) Open Wedge Osteotomy titanium locking plate AP. B) Open Wedge Osteotomy titanium locking plate LAT.
Table 1. Inclusion and exclusion criteria.

\begin{tabular}{c|c}
\hline Inclusion criteria & Exclusion criteria \\
\hline Patients aged $<65$ & Patients aged $>65$ \\
\hline $\begin{array}{c}\text { Isolated medial compartment } \\
\text { arthrosis (Ahlbäck grade 1 or 2) }\end{array}$ & $\begin{array}{c}\text { Ahlbäck grade } 3 \text { arthrosis and } \\
\text { excessive patellofemoral arthrosis }\end{array}$ \\
\hline $\begin{array}{c}\text { Good patient motivation to comply } \\
\text { with postoperative rehabilitation }\end{array}$ & $\begin{array}{c}\text { Poorly patient mentally to comply } \\
\text { with postoperative rehabilitation }\end{array}$ \\
\hline Range of motion $>100^{\circ}$ & Range of motion $<100^{\circ}$ \\
\hline Absence of knee contractures & Flexion contracture of $>10^{\circ}$ \\
\hline $\begin{array}{c}\text { Moderate to severe varus } \\
\text { malalignment (5-150) }\end{array}$ & $\begin{array}{c}\text { Varus gonarthrosis requiring } \\
>20^{\circ} \text { correction }\end{array}$ \\
\hline $\begin{array}{c}\text { Medial joint pain treat to conservative } \\
\text { management (analgesics and/or painkillers } \\
\text { and physiotherapy for at least 1 year) }\end{array}$ & $\begin{array}{c}\text { Incompatible patient to conservative } \\
\text { treatment and poor bone quality } \\
\text { (pre-diagnosed osteoporosis) }\end{array}$ \\
\hline Stable knees & $\begin{array}{c}\text { Laxity of collateral ligament, Anterior } \\
\text { cruciate ligament (ACL) or posterior } \\
\text { cruciate ligament (PCL) insufficiency }\end{array}$ \\
\hline BMl $30 \mathrm{~kg} / \mathrm{m} 2$ & Previous ACL and/or $\mathrm{PCL}$ reconstruction \\
\hline & $\begin{array}{c}\text { Previous bony realignment procedures } \\
\text { to the extensor mechanism }\end{array}$ \\
\hline & Joint infection and rheumatoid arthritis \\
\hline
\end{tabular}

evaluated on AP and lateral radiographs. Union at the osteotomy site follows the same process as normal bone healing. Four of the authors (HS, Cl, MEl, MU) analyzed the radiological data at every follow-up. In addition, two of the authors (HS, Cl) determined when the patients achieved partial and full weight-bearing. The study was approved by the Local Hospital Management Committee. The patients signed the Term of Free and Informed Consent.

\section{Surgical technique}

One hour before surgery, $1 \mathrm{~g}$ cefazolin was administered to all patients intravenously. All patients lay supine under spinal anesthesia. A lower extremity tourniquet was applied in all patients. First, an arthroscopic evaluation was performed and additional intraarticular pathologies were treated using arthroscopic methods. MOWHTO was performed as described elsewhere. ${ }^{15}$ The osteotomy incision was made based on the preoperative plan and a titanium locking OWO plate was placed through this osteotomy incision (Figures 2). Under fluoroscopy, the mechanical axis was determined with a metal rod passing through the center of the femoral head and the ankle. The passage of the mechanical axis through the knee was evaluated by arthroscopy. After achieving sufficient correction, the OWO was fixed using a titanium locking plate. In all patients in Group A, an autograft harvested from the contralateral iliac crest was applied on the osteotomy line. All patients underwent prophylactic treatment to protect against deep vein thrombosis for 10 days.

\section{Postoperative Rehabilitation}

No external immobilizer was applied in any patient. Patient-controlled anesthesia (PCA) was used to manage the postoperative pain and facilitate the rehabilitation process. On postoperative day 1 , active knee $\mathrm{ROM}$ exercises were initiated up to $90^{\circ}$ as tolerated by the patient. After the second week, rehabilitation exercises were continued freely after $\mathrm{ROM}$ of $90^{\circ}$ was achieved. One day after surgery, the patients were mobilized, and walking with the aid of a pair of crutches was permitted. For the first 2 weeks, walking with the heels contacting the ground was permitted. Then, partial weight-bearing was allowed as tolerated by the patient. After 6 weeks, full-weight bearing on a crutch while walking was permitted. Three months postoperatively, the patients walked without support. 

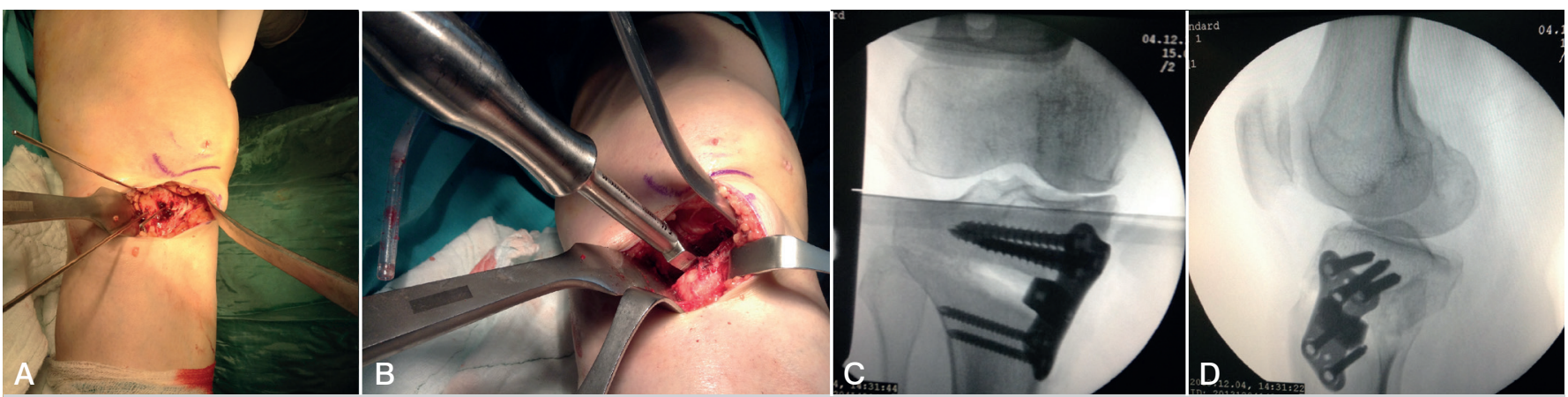

Figure 1. A) Placement of Guide K wires. B) Determination of the size of the Puddu plate to be placed on the osteotomy incision line. C) AP radiogram following perioperative implantation of a plate. D) LAT radiogram following perioperative implantation of a plate.

\section{Statistical Analysis}

The data analysis was performed using the Statistical Package for the Social Sciences software, version 20 for Windows (SPSS Inc., Chicago, IL). The data are shown as mean \pm standard deviation for continuous variables, medians (minimum-maximum) for ordinal variables, and frequencies with per cent for categorical variables. Comparisons between groups were performed using one-way ANOVA with post hoc analysis by Tukey's HSD or independent samples t-test and the Kruskal-Wallis tests or Mann-Whitney U test for normally and abnormally distributed data, respectively. The categorical variables between groups were analyzed using the chi-square test. A p value of $<0.05$ was considered statistically significant.

\section{RESULTS}

\section{Clinical results}

This study included 58 patients (4 men, 54 women; mean age, 52 years; range: $46-59$ years) who were operated on using the MOWHTO method. The patients were followed for at least 1 year. The mean duration of the follow-up was 19.3 months (range: 12-25 months). No significant difference was detected between the groups in the demographic characteristics or size of implants used (Table 2). No significant ( $p>0.05$ ) difference was found between the pre- and postoperative ROM in the patients. The postoperative Knee Society and Functional Knee Society Scores were significantly $(p<0.05)$ different when compared with the preoperative scores in both groups (Table 3 ).

\section{Radiological results}

In Groups A and B, full union of the osteotomy line required 11.85 and 12.15 weeks, respectively; the difference was not significant $(p=0.117)$. After an average of 6 months, radiological bone union was seen. There was no significant $(p>0.05)$ difference in the degree of correction at the first postoperative year between the groups. The X-ray results are summarized in Table 4.

Table 2. Open Wedge Osteotomy plates size.

\begin{tabular}{c|c|c|c}
\hline Plate degrees & $\begin{array}{c}\text { Number of knees } \\
\text { with group } \mathbf{a}(\mathbf{n}=31)\end{array}$ & $\begin{array}{c}\text { Number of knees } \\
\text { with group b }(\mathbf{n}=\mathbf{3 2})\end{array}$ & Percentage (\%) \\
\hline 10 & 13 & 14 & 42,85 \\
\hline 12.5 & 14 & 14 & 44,44 \\
\hline 15 & 4 & 4 & 12,69 \\
\hline
\end{tabular}

Table 3. Knee Society Knee Score and Knee Society Functional Score with pre-operatively and post-operatively at one year after surgery.

\begin{tabular}{c|c|c|c|c}
\hline & KSKS Pre-op. & KSKS Post-op. & KSFS Pre-op. & KSFS Post-op. \\
\hline Group A & $37.9(0-62)$ & $84.2(38-100)$ & $45.9(25-65)$ & $85.5(40-100)$ \\
\hline Group B & $38.1(0-60)$ & $84.9(40-100)$ & $44.5(20-65)$ & $88.2(60-100)$ \\
\hline
\end{tabular}

KSKS: Knee Society Knee Score, KSFS: Knee Society Functional Score.
Table 4.The evaluation of $\mathrm{X}$-ray results.

\begin{tabular}{c|c|c|c}
\hline Group & $\mathbf{A}(\mathrm{N}=31)$ & $\mathbf{B}(\mathrm{N}=32)$ & $\mathbf{p}$ \\
\hline Preop MAD & $29.6 \mathrm{~mm}$ medial & $29.3 \mathrm{~mm}$ medial & 0,885 \\
\hline Early Postop MAD & $5.06 \mathrm{~mm}$ lateral & $5.3 \mathrm{~mm}$ lateral & 0,388 \\
\hline Postop 1 year MAD & $4.9 \mathrm{~mm}$ lateral & $5.1 \mathrm{~mm}$ lateral & 0,402 \\
\hline PreopaMPTA & $81.3^{0}\left(77^{0}-86^{0}\right)$ & $81.8^{0}\left(76^{0}-87^{0}\right)$ & 0,459 \\
\hline Early Postop aMPTA & $91.1^{0}\left(87^{0}-97^{0}\right)$ & $91.4^{0}\left(86^{0}-97^{0}\right)$ & 0,757 \\
\hline Postop 1 Year aMPTA & $90.5^{0}\left(86^{0}-97^{0}\right)$ & $91^{0}\left(85^{0}-97^{0}\right)$ & 0,571 \\
\hline $\begin{array}{c}\text { Correction degrees } \\
\text { of post-operation }\end{array}$ & $10.39^{0}$ & $10.31^{0}$ & 0,817 \\
\hline $\begin{array}{c}\text { Correction degrees of post- } \\
\text { operation at 12 months }\end{array}$ & $9.97^{0}$ & $9.94^{0}$ & 0,918 \\
\hline $\begin{array}{c}\text { Difference of } \\
\text { correction degrees }\end{array}$ & $0.42^{0}$ & $0.39^{0}$ & 0,910 \\
\hline Preop ISI & $1,05(0,79-1,22)$ & $1,01(0,79-1,25)$ & 0,260 \\
\hline Postop ISI & $1,12(0,8-1,35)$ & $1,09(0,81-1,35)$ & 0,534 \\
\hline Postop ISI at 12. months & $1,14(0,82-1,36)$ & $1,13(0,84-1,36)$ & 0,854 \\
\hline Preop BPR & $0,98(0,77-1,12)$ & $0,94(0,75-1,14)$ & 0,094 \\
\hline Postop BPR & $0,94(0,77-1,06)$ & $0,90(0,75-1,05)$ & 0,099 \\
\hline Postop BPR at 12. months & $0,92(0,76-1)$ & $0,88(0,75-1)$ & 0,100 \\
\hline
\end{tabular}

MAD: Mechanical axis deviation, aMPTA: Angle between tibial anatomical axis and the articular surface of the proximal tibia and anteroposterior images, ISI: Insall-Salvatiindex BPR:Blackburne-Peelratio.

\section{Complications}

None of the patients developed a neurovascular injury, serious infection, or patellar dislocation. Twelve (19\%) patients developed various complications: four patients had lateral cortex fractures during the osteotomy procedure (a short-thread cancellous screw was placed through the hole of the plate crosswise at the osteotomy line and the other screws placed in the plate were locking screws; see (Figure 3); three developed deep hematomas in the muscle; three Group A patients had chronic tenderness at the iliac graft harvesting site; and two patients developed lateral plateau fractures while expanding the osteotomy line [after fixing the plate with two spongious screws, the osteotomy line was opened until required correction was achieved (Figure 4); the time to bone union was not different in these patients and no correction deficit developed.

\section{DISCUSSION}

MOWHTO, which is a treatment alternative for young and active patients with medial gonarthrosis of the knee, has improved mid-and long-term outcomes with appropriate patient selection and attentive surgery. ${ }^{1-5}$ With MOWHTO technique, no implant is applied at the joint surface, no septic or aseptic loosening is detected (as seen in arthroplasty) and, most importantly, total knee arthroplasty is postponed by preserving the integrity of the patient's own anatomy. ${ }^{6-8,16}$ 


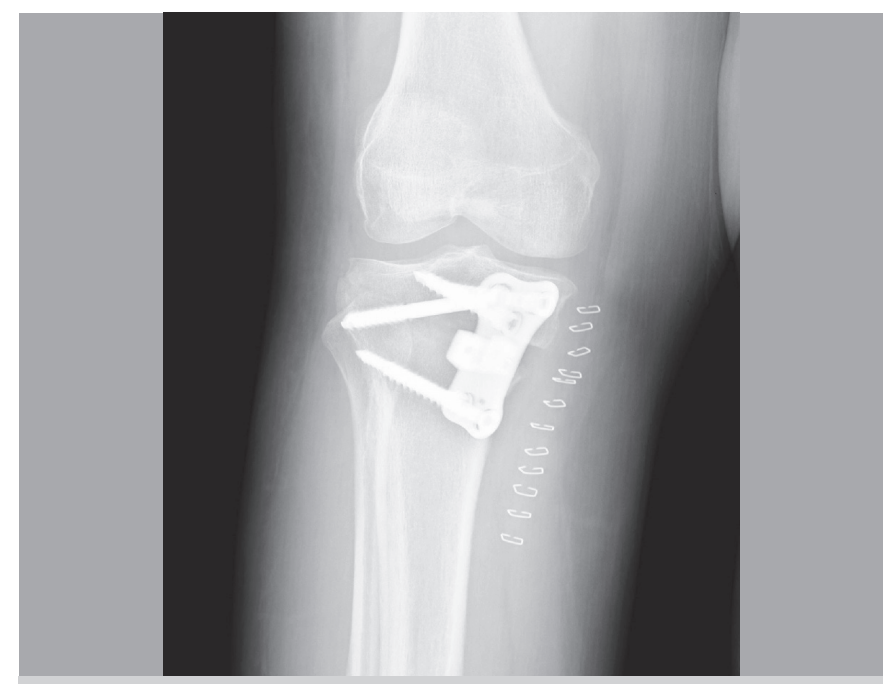

Figure 3. AP radiogram of the patient who developed lateral cortex fracture.

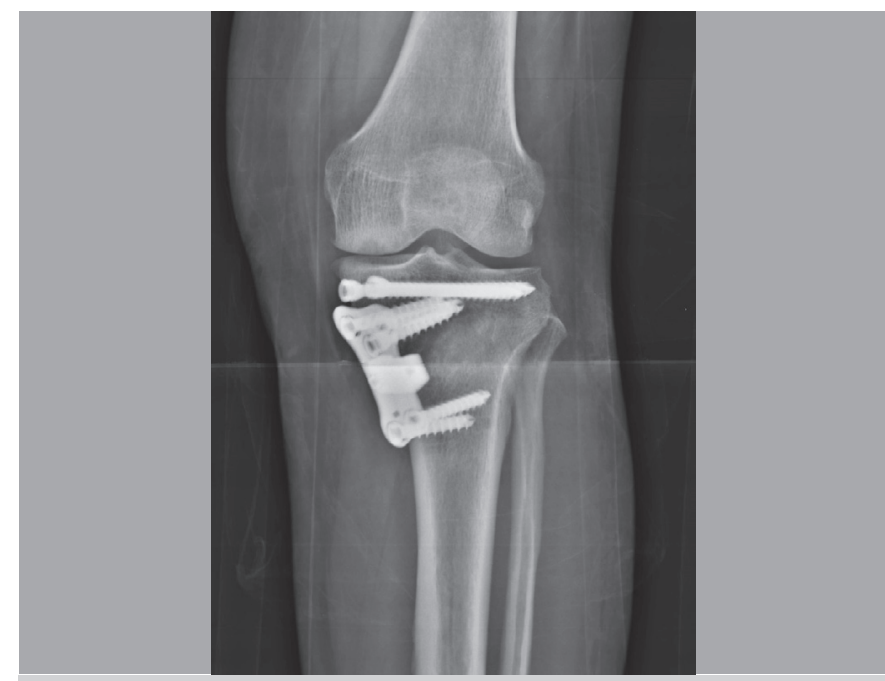

Figure 3. AP radiogram of the patient with lateral plateau fracture.

MOWHTO is associated with stability of the osteotomy in accordance with osteotomy size, an intact lateral cortex, and rigid fixation..$^{10}$ Even if these criteria are met, with MOWHTO it is not always possible to achieve the desired state of wellbeing. Serious problems include problematic union of the osteotomy line, unwanted fractures, and under- and overcorrection. Grafting of the osteotomy line is directed at preventing problematic bone union. When a fracture occurs, union can be problematic and a correction deficit can occur despite rigid fixation. During surgery, the correction should be at least $80^{\circ}$ valgus with a tendency towards rigid fixation. ${ }^{6,10,12,14-16}$

With MOWHTO, although the use of autografts is frequently preferred, this increases the operating time, pain at the donor site, and the risks of iliac wing fracture and inflammation. The disadvantages of allografts, which are being used increasingly, include lower bone formation rates, contagious diseases, and higher costs. ${ }^{6,79,10}$ To prevent correction deficits and accelerate bone healing, Spahn ${ }^{18}$ recommends the use of grafts for osteotomy defects $>12^{\circ}$, and tibial size effects on wedge height. In our series, three Group A patients developed chronic pain at the donor site, which was consistent with the literature. We did not observe any significant differences between the groups with and without grafts in terms of union of the osteotomy line or correction deficit. Additionally, the tibial wedge heights of our groups were similar, and was not observed any significant differences between the groups with and without grafts in terms of union of the osteotomy line or correction deficit. Therefore, it is not necessary to risk additional morbidity and potential complications by using grafting in patients who are undergoing MOWHTO with rigid fixation. However, correction degrees of post-operation at 12 months were approximately 10 degrees. It was not than 12 degrees.

Many studies have demonstrated consolidation in patients who underwent MOWHTO with rigid locking plates without using grafts. ${ }^{18,19}$ Correction deficits were reported in cases with lateral cortex fractures when adequate stabilization could not be achieved using conventional Puddu stainless steel plates. ${ }^{6,9,10,14,16}$ We think that the use of an OWO titanium locking plate and a $6.5 \mathrm{~mm}$ shortthread cancellous screw inserted through the screw holes in the plate provided additional stabilization of the fracture line.

El-Azab et al. demonstrated that closing-wedge HTO and opening-wedge HTO increased the incidences of patella alta and patella baja, respectively. ${ }^{20}$ In our series, the development of patella baja was seen in patients with MOWHTO. However, there were no significant differences between the pre- and postoperative measurements of the length of the patellar tendon, ISI, and IBR.

Study limitations included its retrospective nature, the performance of the surgeries by different surgeons in the groups with and without graft implantation, the inability to assess the smoking status or number of pack-years of the participants, the wide age range, and the small sample size.

\section{CONCLUSION}

In patients undergoing MOWHTO using an OWO titanium locking plate, the use of a graft does not make an additional contribution to the time to bone union or preservation of the correction achieved, while not using a graft avoids the development of additional comorbidities that might occur with an allograft or autograft. We also believe that not using a graft decreases the operating time and costs.

AUTHORS' CONTRIBUTIONS: This manuscript, which describes a multi-institutional study, has four authors. Each author contributed individually and significantly to the development of the manuscript. HS (0000-0003-2221-4731)* and $\mathrm{Cl}(0000-0002-9750-9350)^{*}$ were the main contributors to the manuscript. HS and $\mathrm{Cl}$ performed at the different medical centers, followed the patients, and gathered the clinical data. $\mathrm{HS}, \mathrm{Cl}, \mathrm{MEI}(0000-0002-5385-6182)^{\star}$, and MU (0000-0003-3139-3583)* analyzed the radiological data at every follow-up appointment. In addition, two of the authors (HS, Cl) determined when the patients achieved partial and full weight-bearing. $\mathrm{HS}$ and $\mathrm{Cl}$ performed the statistical analysis. $\mathrm{HS}, \mathrm{Cl}, \mathrm{MEl}$, and MU performed the literature search, reviewed the manuscript, and contributed to the intellectual concept of the study. ${ }^{\star}$ ORCID (Open Researcher and Contributor ID).

\section{REFERENCES:}

1. Gomes JLE, Ruthner RP, Marczyk LRS. Valgus tibial osteotomy with" wedge" plate of Puddu: technique presentation. Acta Ortop Bras. 2000;8(3):134-9.

2. Staubli AE, Jacob HA. Evolution of open-wedge high-tibial osteotomy: experience with a special angular stable device for internal fixation without interposition material. Int Orthop. 2010;34(2):167-72.

3. Jackson J. Osteotomy for osteoarthritis of the knee. J Bone Joint Surg Br.
1958;40(4):826-6.

4. Coventry MB. Osteotomy of the upper portion of the tibia for degenerative arthritis of the knee. A preliminary report. 1965. J Bone Joint Surg Am. 1989; 47(5):984 -90.

5. Longino PD, Birmingham TB, Schultz WJ, Moyer RF, Giffin JR. Combined tibial tubercle osteotomy with medial opening wedge high tibial osteotomy minimizes 
changes in patellar height: a prospective cohort study with historical controls. Am J Sports Med. 2013;41(12):2849-57.

6. Vena G, D'Adamio S, Amendola A. Complications of osteotomies about the knee. Sports Med Arthrosc. 2013;21(2):113-20.

7. Cho SW, Kim DH, Lee GC, Lee SH, Park SH. Comparison between Autogenous Bone Graft and Allogenous Cancellous Bone Graft in Medial Open Wedge High Tibial Osteotomy with 2-Year Follow-up. Knee Surg Relat Res. 2013;25(3):117-25.

8. Hankemeier S, Mommsen P, Krettek C, Jagodzinski M, Brand J, Meyer C, et al. Accuracy of high tibial osteotomy: comparison between open- and closed-wedge technique. Knee Surg Sports Traumatol Arthrosc. 2010;18(10):1328-33.

9. Brosset T, Pasquier G, Migaud H, Gougeon F. Opening wedge high tibia osteotomy performed without filling the defect but with locking plate fixation (TomoFix) and early weight-bearing: prospective evaluation of bone union, precision and maintenance of correction in 51 cases. Orthop Traumatol Surg Res. 2011;7(7):705-11.

10. El-Assal MA, Khalifa YE, Abdel-Hamid MM, Said HG, Bakr HM. Opening-wedge high tibial osteotomy without bone graft. Knee Surg Sports Traumatol Arthrosc. 2010;18(7):961-6.

11. Gouin F, Yaouanc F, Waast D, Melchior B, Delecrin J, Passuti N. Open wedge high tibial osteotomies: Calcium-phosphate ceramic spacer versus autologous bonegraft. Orthop Traumatol Surg Res. 2010;96(6):637-45.

12. Maffulli N, Loppini M, Longo UG, Denaro V, Oliva F. Bovine xenograft locking Puddu plate versus tricalcium phosphate spacer non-locking Puddu plate in opening-wedge high tibial osteotomy: a prospective double-cohort study. Int Orthop. 2013;37(5):819-26
13. Zorzi AR, da Silva HG, Muszkat C, Marques LC, Cliquet A Jr., de Miranda JB. Opening-wedge high tibial osteotomy with and without bone graft. Artif Organs. 2011;35(3):301-7.

14. Martin R, Birmingham TB, Willits K, Litchfield R, Lebel ME, Giffin JR. Adverse event rates and classifications in medial opening wedge high tibial osteotomy. Am J Sports Med. 2014;42(5):1118-26.

15. Asik M, Sen C, Kilic B, Goksan SB, Ciftci F, Taser OF. High tibial osteotomy with Puddu plate for the treatment of varus gonarthrosis. Knee Surg Sports Traumatol Arthrosc. 2006;14(10):948-54.

16. Atrey A, Morison Z, Tosounidis T, Tunggal J, Waddell JP. Complications of closing wedge high tibial osteotomies for unicompartmental osteoarthritis of the knee. Bone Joint Res. 2012;1(9):205-9.

17. Spahn G. Complications in high tibial (medial opening wedge) osteotomy. Arch Orthop Trauma Surg. 2004;124(10):649-53.

18. Schroter S, Ateschrang A, Lowe W, Nakayama H, Stockle U, Ihle C. Early full weight-bearing versus 6-week partial weight-bearing after open wedge high tibial osteotomy leads to earlier improvement of the clinical results: a prospective, randomised evaluation. Knee Surg Sports Traumatol Arthrosc. 2017;25(1):325-32

19. Kim MK, Ha JK, Lee DW, Nam SW, Kim JG, Lee YS. No correction angle loss with stable plates in open-wedge high tibial osteotomy. Knee Surg Sports Traumatol Arthrosc. 2015; 23(7):1999-2006.

20. El-Azab H, Glabgly P, Paul J, Imhoff AB, Hinterwimmer S. Patellar height and posterior tibial slope after open- and closed-wedge high tibial osteotomy: a radiological study on 100 patients. Am J Sports Med. 2010;38(2):323-9 